\title{
Intellectual Labor and Pedagogical Work: Rethinking the Role of Teacher as Intellectual'
}

\author{
Henry A. Giroux \\ Miami University
}

A curious problem haunts the discourse regarding the crisis facing public education in the United States. ${ }^{2}$ On the one hand, this crisis is characterized as a failure of the schools to prepare students adequately for the ever changing demands of a sophisticated technological economy. It is also described by less vocal critics as the growing failure of schools to prepare students to think critically and creatively with regard to developing the sophisticated literacy skills necessary to make informed and effective choices about the worlds of work, politics, culture, personal relationships, and the economy. Underlying both sets of criticisms is the notion that schools have failed to take the issues of excellence and creativity seriously and in doing so have undermined the economic and academic possibilities that could be conferred upon both students and the larger society.

On the other hand, educational reformers have responded to the crisis in public education by primarily offering solutions that either ignore the role of teachers in preparing learners to be active and critical citizens, or they suggest reforms that ignore the intelligence, judgment, and experience that teachers might bring to bear on such issues. The call for excellence and improved student creativity has been accompanied by policy suggestions that further erode the power teachers have over the conditions of their work, while simultaneously proposing that administrators and teachers look outside of their schools for improvements and needed reforms. The result is that many of the educational reforms appear to reduce teachers to the status of low-level employees or civil servants whose main function seems to be to implement reforms decided by experts in the upper levels of state and educational bureaucracies. Furthermore, such reforms embrace technological solutions that undermine the historical and cultural specificity of school life and further weaken the possibilities for school administrators and teachers to work with local parents and groups in improving schools from the vantage point of concrete educational needs and interests. Underlying the paradox at work in the discourse of school reform is a dual failure. First, there is the growing public failure to recognize the central role that teachers must play in any viable attempt to revitalize the public schools. Secondly, there is the failure to recognize that the ideological and political interests underlying the dominant thrusts in school reform are at odds with the traditional role of organizing public education around the need to educate students for the main- 
tenance and defense of the traditions and principles necessary for a democratic society.

I want to argue that part of the growing crisis in public education centers around the declining competence of students and others to effectively interrogate and communicate ideational content. In other words, what is in jeopardy is not merely the ability of students to be creative, but the very capacity for conceptual thought itself. Moreover, since democratic, social, cultural, and political forms depend on a self motivated and autonomous public, the precondition for which is critical thinking, the crisis at hand may be the very existence of democracy itself.

My main point will be that the crisis in creativity and critical learning has in large part to do with the developing trend toward the disempowerment of teachers at all levels of education. This involves not only a growing loss of power among teachers around the basic conditions of their work, but also a changing perception of their role as reflective practitioners. In effect, I will argue that teacher work is being increasingly situated within a technical and social division of labor that reduces teachers to the dictates of experts removed from the context of the classroom and serves to widen the political gap between those who control the schools and those who actually deal with curricula and students on a day-to-day basis. In the first instance, teachers are relegated to instrumental tasks that require little or no space for oppositional discourse and social practices. Pedagogy, in this case, is reduced to the implementation of taxonomies that subordinate knowledge to forms of methodological reification, while theories of teaching are increasingly technicized and standardized in the interest of efficiency and the management and control of discrete forms of knowledge. ${ }^{3}$

Teachers are not simply being proletarianized, the changing nature of their roles and function signifies the disappearance of a form of intellectual labor central to the nature of critical pedagogy itself. Moreover, the tendency to reduce teachers to either high level clerks implementing the orders of others within the school bureaucracy or to the status of specialized technicians is part of a much larger problem within Western societies, a problem marked by the increasing division of intellectual and social labor and the increasing trend towards the oppressive management and administration of everyday life. The current tendency to reformulate the status and nature of teacher work needs to be specified briefly before I argue for an alternative view of how teacher work should be viewed, and what the implications might be for a critical theory of schooling.

\section{Toward a Proletarianization of Teacher Work}

Historically, the relationship between the role of educators and the larger society has been mediated by the image of the school teacher 
as a dedicated public servant reproducing the dominant culture in the interest of the common good, and the university community as a body of social scientists who in their capacity as experts "were to educate the masses and provide direction for moral and social progress." With the advent of the twentieth century, the administration and organization of public schools were increasingly brought under the influence of the instrumental ideologies of corporate business interests; moreover, the growing professionalization of academics and their respective disciplines resulted in a redefinition of the theoretical nature of the social sciences. Increasingly, university social scientists shifted from the terrain of social reform to the role of expert as policy advisor. Within this context, the relationship between knowledge and power took on a new dimension as the development of social science became closely linked to supporting the ideological and social practices of a business society. In charting the rise and success of the academic social sciences, Silva and Slaughter ably document how the emerging professional associations of the developing social sciences between 1865 and 1910 in the United States lent their skills and knowledge to the economic and social problems faced by the rising corporate liberal interests. In commenting on the rise of the American Economic Association, they provide an insight into the general political direction in which the professional associations and the social sciences in general were moving:

As economists were more routinely called to expert service and initiated in the politics of power, they refined their notion of constituency. Although using the rhetoric of objective science and the public welfare, their clientele was the Progressive wing of corporate capital and other professionals. . . Claiming to be impartial and scientific arbiters of social questions, they used the ideology of expertise in the interests of social control and developed pragmatic, technical mechanisms to consolidate and finance colonial fiscal policy, federal industrial relations commissions, and the income tax. Thus, social science experts became advocates for the existing order, hegemonic intellectuals serving the emerging national corporate elite. ${ }^{5}$

The theoretical tenets of the natural sciences began to provide the model for dominant academic discourse and inquiry in the social sciences. This move tended to reduce critical thought and reason to its merely technical dimensions. Within this positivistically oriented discourse, research techniques became increasingly freed from value judgments, useful knowledge was measured next to its managerial capabilities, and science became synonymous with the search for transhistorical laws and the requirement that theory explain rather than constitute or determine the object under analysis. ${ }^{6}$

It is important to stress that the primacy of technical and economic rationality did more than devalue the importance of moral and religious reason in everyday life; it also strengthened relations of de- 
pendency and powerlessness for ever widening groups of people through the social practices of an industrial ideology and psychology that reached far into the culture industry and other spheres of public life. ${ }^{7}$ Underlying this technical rationality and its accompanying rationalization of reason and nature was a call for the separation of conception from execution, the standardization of knowledge in the interest of managing and controlling it, and the devaluation of critical intellectual work for the primacy of practical considerations. The history of this emerging technocratic rationality in both the schools and in public life has been repeated many times, and it need not be reinvented here, but its effects have taken on a special significance in the 1980s and can be seen in a number of areas. ${ }^{8}$

One area in which the dominance of technocratic rationality is manifest is in the training of prospective teachers. As Kliebard, ${ }^{9}$ Zeichner, ${ }^{10}$ and others ${ }^{11}$ have pointed out, teacher education programs in the United States have long been dominated by their behavioristic orientation towards issues of mastery and methodological refinement as the basis for developing teacher competence. The normative and political implications of this approach are made clear by Zeichner:

Underlying this orientation to teacher education is a metaphor of "production," a view of teaching as an "applied science" and a view of the teacher as primarily an "executor" of the laws and principles of effective teaching. Prospective teachers may or may not proceed through the curriculum at their own pace and may participate in varied or standardized learning activities, but that which they are to master is limited in scope (e.g., to a body of professional content knowledge and teaching skills) and is fully determined in advance by others often on the basis of research on teacher effectiveness. The prospective teacher is viewed primarily as a passive recipient of this professional knowledge and plays little part in determining the substance and direction of his or her preparation program. ${ }^{12}$

Within this overly behavioristic model of education, teachers are viewed less as creative and imaginative thinkers, who can transcend the ideology of methods and means in order to critically evaluate the purpose of educational discourse and practice, than as obedient civil servants dutifully carrying out the dictates of others. All too often teacher education programs lose sight of the need to educate students to be teacher-scholars by developing educational courses that focus on the immediacy of school problems and substitute the discourse of management and efficiency for a critical analysis of the underlying conditions that structure school life. Instead of helping prospective teachers to think about who they are and what they should do in classrooms, or what their responsibility might be in interrogating the means and ends of specific school policy, students are often trained to share techniques on how to control student discipline, teach a given subject effectively, organize a day's activities 
as efficiently and in as orderly a way as possible. The emphasis is on finding out what works! The form of technical rationality that underlies this type of educational training is not confined to undergraduate programs. Its logic exercises a strong influence on graduate programs as well, programs that are often intended to promote what is euphemistically called "educational leadership." For instance, it was noted in a recent study of doctoral programs in education that "Research in education is preoccupied with techniques, rather than with the inquiry into the nature and course of events - with 'how to' rather than 'what,' with form rather than substance. ... Too often students in education ... have difficulty even finding serious questions worth addressing." 13

If prospective teachers are often trained to be specialized technicians, future school administrators are trained in the image of the social science expert. Richard Bates ${ }^{14}$ and William Foster, ${ }^{15}$ for instance, have pointed out that much of the training for school administrators, principals, and superintendents is narrowly technical, concerned primarily with producing a marriage between organization theory and the principles of "sound" business management. Inherent in such training is the notion that complex language systems, management controls, and systems of accountability are beyond the grasp of either teachers or the average layperson. The technocratic consciousness embodied in this view is not only at odds with the notion of decentralized control and the principles of participatory democracy, it also presents an ahistorical and depoliticized view of school governance and policy. Schools are not seen as sites of struggle over different orders of representation, or as sites that embody particular configurations of power that shape and structure activities of classroom life. On the contrary, schools become reduced to the sterile logic of flow, charts, a growing separation between teachers and administrators, and an increasing tendency toward bureaucratization. Thus the logic of technocratic rationality serves to remove teachers from participating in a critical way in the production and evaluation of school curricula. For example, the form that school knowledge takes and the pedagogy used to legitimate it become subordinated to the principles of efficiency, hierarchy, and control.

One consequence is that decisions and questions over what counts as knowledge, what is worth teaching, how one judges the purpose and nature of instruction, how one views the role of school in society, and what the latter implies for understanding how specific social and cultural interests shape all levels of school life, is removed from the collective influence of teachers themselves. The relationship between the bureaucratization of schools and the specific structuring of knowledge is illuminated in the following: 
nents or relatively discrete components; that the units of knowledge be ordered in sequence; that the knowledge be communicable from one person to another using conventional media of communication; that success in acquisition of part, if not most, of the knowledge is recordable in quantifiable form; that the knowledge be objectified in the sense of having an existence independent of its human origins; that the knowledge is stratified into various levels of status or prestige; that knowledge based upon concrete experience be treated as low status, but that knowledge expressed in abstract and generalized principles be regarded as having high status. ${ }^{16}$

The increasing tendency to reduce teacher autonomy in the development and planning of curricula is also evident in the production of prepackaged curriculum materials that contribute to a form of deskilling among teachers. For instance, Apple ${ }^{17}$ has pointed to elementary school science curricula packages whose underlying rationality oriented teachers to simply carrying out predetermined content and instructional procedures. Similarly, the principles at work in this rationality are also found in many school textbooks and management pedagogies. In many school textbooks knowledge is broken down into discrete parts, standardized for easier management and consumption, and published with the intent of being marketed for large general student audiences..$^{18}$ Furthermore, there is a growing adoption by schools of forms of pedagogy that routinize and standardize classroom instruction. This is evident in the proliferation of instructional based curricula and management schemes, competency based learning systems, and similar approaches such as mastery learning. These are basically management pedagogies because the central question regarding learning is reduced to the problem of management, that is, "how to allocate resources (teachers, students, and materials) to produce the maximum number of certified ... students within a designated time."

The principles underlying management pedagogies are at odds with the notion that teachers should be actively involved in producing curricula materials suited to the cultural and social contexts in which they teach. Questions regarding cultural specificity, teacher judgment, and how student experiences and histories relate to the learning process itself are ignored. One could go even further and say that the issues embodied in such questions represent a mode of teacher autonomy and control that are a positive hindrance to those school administrators who believe that excellence is a quality to be displayed primarily in higher reading, math, and college board scores. This becomes more obvious in light of the major assumption underlying management pedagogy: that the behavior of teachers needs to be controlled and made consistent and predictable across different schools and student populations. The pay-off for school systems is not merely the touting of more manageable forms of pedagogy. This type of school policy also makes for good public relations in that school administrators can provide technical solutions 
to the complex social, political, and economic problems that plague their schools while simultaneously invoking the principles of accountability as an indicator of success. In other words, if the problem can be measured, it can be solved. The following statement by some Chicago school administrators enamored of management pedagogy points to the ideology behind the growing proletarianization and deskilling of teacher work:

Providing materials that were centrally developed and successfully field tested would: 1) reduce greatly the time needed to prepare and organize materials; 2) require little inservice time; 3) be economical for schools in Chicago and elsewhere to implement; 4) standardize the definition, sequencing, and quality of instruction necessary for mastery of each objective; 5) reduce greatly the time needed for developing lesson plans; and 6 ) be easy for substitutes to use. ${ }^{20}$

Underlying this approach to educational reform is a mode of technocratic rationality that restricts curricula and student diversity and simultaneously refuses to address seriously the issue of how to deal pedagogically with less privileged learners. In the first instance, the narrowing of curricula choices to a back-to-basics format, and the introduction of lock-step, time-on-task pedagogies operates from the pedagogically erroneous assumption that all students can learn from the same materials, pedagogies, and modes of evaluation. The notions that students come from different histories, embody different experiences, linguistic practices, cultures, and talents is ignored. Similarly, the current drive among school reformers to deny a high school diploma to students who don't pass a comprehensive graduating exam, or to deny entrance to undergraduate and graduate schools to students who don't measure up to the call for higher scores on any one of a number of tests represents a technological solution to a highly charged political and social problem. The central issue that needs to be interrogated is how public schools and institutions of higher education might be systematically failing certain groups of students, or how they might re-evaluate the nature and structure of their own approaches to teaching and learning so as to take seriously their obligation to educate all students to be productive citizens. K. Patricia Cross sums the problem up well:

Clearly, we cannot afford to "improve" educational institutions at the expense of society. But it is distressing to see how many well-meaning but short-sighted legislators and educators are taking advantage of the current mandates for excellence by supporting proposals that can have the effect of eliminating from local high schools and colleges the very students who need them most. Some years ago, a wag said of Admiral Hyman Rickover's elitist recommendations for education, "Save the best; shoot the rest." Selection is the easy route to quality-but it is a swinging-pendulum solution that fails to address the underlying problems of curriculum, instruction, and teacher training. ${ }^{21}$ 


\section{Rethinking the Nature of the Intellectual}

What I have tried to do in the previous section is point to the various ideological and material forces at work in the United States that currently undermine the conditions of work necessary for teachers to assume the posture of thoughtful, critical, educational leaders. In what follows, I want to argue that one way to rethink and restructure the nature of teacher work is to view teachers as intellectuals. The category of intellectual is helpful in a number of ways. First, it provides a theoretical basis for examining teacher work as a form of intellectual labor. Secondly, it clarifies the ideological and material conditions necessary for intellectual work. Thirdly, it helps to illuminate the various modes of intelligibility, ideologies, and interests that are produced and legitimated by teacher work.

By viewing teachers as intellectuals, we can illuminate and recover the rather general notion that all human activity involves some form of thinking. That is, no activity, regardless of how routinized it might become, is abstracted from the functioning of the mind in some capacity. This is a crucial issue because by arguing that the use of the mind is a general part of all human activity, we dignify the human capacity for integrating thinking and practice and in doing so highlight the core of what it means to view teachers as reflective practitioners. Within this discourse, teachers can be seen not merely as "performers professionally equipped to realize effectively any goals that may be set for them. Rather, [they should] be viewed as free men and women with a special dedication to the values of the intellect and the enhancement of the critical powers of the young. ${ }^{22}$

Furthermore, viewing teachers as intellectuals provides a strong critique of those ideologies that legitimate social practices that separate conceptualization, planning, and designing from the processes of implementation and execution. It is important to stress that teachers must take active responsibility for raising serious questions about what they teach, how they are to teach it, and what the larger goals are for which they are striving. This means that they must take a responsible role in shaping the purposes and conditions of schooling. Such a task is difficult within a division of labor where teachers have little influence over the ideological and economic conditions of their work. Moreover, there is a growing political and ideological tendency as expressed in the current debates on educational reform to abstract teachers and students from their histories, cultures, and experiences in the name of pedagogical approaches that will make schooling more instrumental, which generally means that teachers and students alike are "situated" within curricula approaches and instructional management schemes that reduce their roles to either implementing or receiving the goals and objectives of publishers, outside experts, and others far removed from the specificities of daily classroom life. This issue becomes all the more important 
when seen as part of the growing objectification of human life in general. The concept of teacher as intellectual provides the theoretical posture to fight against this type of ideological and pedagogical imposition.

Moreover, the concept of intellectual provides the basis for interrogating the specific ideological and economic conditions under which intellectuals as a social group need to work in order to function as critical, creative human beings. This last point takes on a normative and political dimension and seems especially relevant for teachers. For if we believe that the role of teaching cannot be reduced to merely training in the practical skills, but involves instead the education of a group of intellectuals vital to the development of a democratic society, then the category of intellectual becomes a way of linking the purpose of teacher education, public schooling, and inservice training to the very principles necessary for the development of a democratic order and society.

Neither teacher training institutions nor the public schools themselves have seriously viewed themselves historically as important sites for educating teachers as intellectuals. In part, this has been due to the pervasiveness of a growing technocratic rationality that separates theory from practice and contributes to the development of modes of pedagogy that ignore teacher creativity and insight; it is also due to the predominance of theories and forms of school leadership and organization that give teachers little control over the nature of their work. The latter not only shape the structure and experiences of what teachers do in schools, but also the way in which they are prepared in teacher training institutions. What is generally overriding in most teacher education programs is the emphasis on having prospective educators master pedagogical techniques that generally eschew questions of purpose and the discourse of critique and possibility.

I have argued that by viewing teachers as intellectuals we can begin to rethink and reform those historical traditions and conditions that have prevented schools and teachers from assuming their full potential as active, reflective scholars and practitioners. But I want to both qualify this point and extend it further. I believe that it is imperative not only to view teachers as intellectuals, but also to contextualize in political and normative terms the concrete social functions that teachers perform. In this way, we can be more specific about the different relationships that teachers have both to their work and to the society in which such work takes place. I want to develop this position in a more detailed way below.

Any attempt to reformulate the role of teachers as intellectuals has to also include the broader issue of how to view educational theory in general. It is imperative to view educational theory as a form of social theory. I say imperative because if seen as a form of social the- 
ory, the discourse of educational theory can be understood and interrogated as representing forms of knowledge and social practice that legitimate and reproduce particular forms of social life. Educational theory in this case is not viewed as merely the application of objective scientific principles to the concrete study of schooling and learning. Instead, it is seen as an eminently political discourse that emerges from and characterizes an expression of struggle over what forms of authority, orders of representation, forms of moral regulation, and versions of the past and future should be legitimated, passed on, and debated within specific pedagogical sites. All forms of educational theory and discourse represent a form of ideology that has an intimate relation to questions of power. This is evident in the way such discourses arise out of and structure the distinctions between high and low status knowledge, legitimate cultural forms that reproduce specific class, racial, and patriarchal interests, and help to sustain specific organizational patterns and classroom social relations.

Educational theory should also be seen as having a deep commitment to developing schools as sites that prepare students to participate in and struggle to develop democratic public spheres. This means that the value of educational theory and practice should be linked to providing the conditions for teachers and students to understand schools as public spheres dedicated to forms of self and social empowerment. It also means defining teacher work against the imperative to develop knowledge and skills that provide students with the tools they will need to be leaders rather than simply managers or skilled civil servants. Similarly, it means fighting against those ideological and material practices that reproduce privileges for the few and social and economic inequality for the many.

By politicizing the notion of schooling and revealing the ideological nature of educational theory and practice, it becomes possible to be more specific in defining the meaning of the category of the intellectual and to interrogate the political and pedagogical function of the intellectual as a social category. There are two related but separate points by which to venture a definition of the intellectual. The more general definition is rooted in a quality of mind that is characterized as having a creative, critical and contemplative relationship to the world of ideas. Richard Hofstadter epitomizes this position in his distinction between the meaning of intellect and the meaning of intelligence. Intelligence, for him, is "an excellence of mind that is employed within a fairly narrow, immediate predictable range; it is a manipulative, adjustive, infailingly practical quality. . . . Intellect, on the other hand, is the critical, creative, and contemplative side of mind. Whereas intelligence seeks to grasp, manipulate, reorder, adjust, intellect examines, ponders, wonders, theorizes, criticizes, imagines." $^{23}$ 
Paul Piccone provides a similar distinction but places it within a larger social context:

Unless one fudges the definition of intellectuals in terms of purely formal and statistical educational criteria, it is fairly clear that what modern society produces is an army of alienated, privatized, and uncultured experts who are knowledgeable only within very narrowly defined areas. This technical intelligentsia, rather than intellectuals in the traditional sense of thinkers concerned with the totality, is growing by leaps and bounds to run the increasingly complex bureaucratic and industrial apparatus. Its rationality, however, is only instrumental in character, and thus suitable mainly to perform partial tasks rather than tackling substantial questions of social organization and political direction. ${ }^{24}$

Herb Kohl is more specific and provides a definition of the intellectual that relates it directly to teachers. He writes:

An intellectual is someone who knows about his or her field, has a wide breadth of knowledge about other aspects of the world, who uses experience to develop theory and questions theory on the basis of further experience. An intellectual is also someone who has the courage to question authority and who refuses to act counter to his or her own experience and judgment. ${ }^{25}$

In my view all of these positions make distinctions that are important but fall into the problem of suggesting that intellectual inquiry is either the repository of specific groups of people or that the quality of intellectual inquiry is only operative within specific social functions. This is not meant to suggest that the question of what qualities of mind constitute intellectual inquiry is not an important one. These positions are informative in that they suggest that intellectual inquiry is characterized by someone who has a breadth of knowledge about the world, who views ideas in more than instrumental terms, and who harbors a spirit of inquiry that is critical and oppositional, one that is true to its own impulses and judgments. But a distinction has to be made in this case between those characteristics of intellectual inquiry as they exist in various degrees and proportions among different individuals and the social function of intellectual work itself.

\section{Notes}

1. Part II of this article will appear in Volume 3, No. 2. This paper draws upon and expands a number of ideas that will appear in my forthcoming book (with Stanley Aronowitz), Education under siege, South Hadley, MA: Bergin \& Garvey.

2. The discourse of crisis in public education has been dealt with in a series of reports and books, including the following: The National Commission on Excellence (1983), A nation at risk: The imperative for educational reform, Washington, DC; Task Force on Education for Economic Growth 
(1983), Action for excellence: A comprehensive plan to improve our nation's schools, Denver: Education Commission of the States; The College Entrance Examination Board (1983), Academic preparation for college, New York: Author; Twentieth Century Fund Task Force on Federal Elementary and Secondary Education Policy (1983), Making the grade, New York: Author; Carnegie Corporation of New York (1983), Education and economic progress: Toward a national educational policy, New York: Author; John Goodland (1984), A place called school: Promise for the future, New York: McGraw-Hill; Ernest L. Boyer (1983), High school: A report on American secondary education, New York: Harper \& Row; Theodore Sizer (1984), Horace's compromise: The dilemma of the high school, Boston: Houghton Mifflin. For a critical analysis of these reports and the ideologies behind them, see Stanley Aronowitz and Henry Giroux (in press), Education under siege, South Hadley, MA: Bergin \& Garvey.

3. An example of this trend in the teaching reading through a mastery learning approach can be found in Patrick Shannon (1984, September), Mastery learning in reading and the control of teachers and students, Language Arts, 61(5), 484-493. There is a long history of this tradition in North America, especially in the US. See Raymond Callahan (1962), Education and the cult of efficiency, Chicago: University of Chicago Press.

4. Thomas S. Popkewitz (1984), Paradigm and ideology in educational research, Philadelphia and London: The Falmer Press, p. 108.

5. E. T. Silva and S. Slaughter (1981), Prometheus/bound: Knowledge, power, and the transformation of American social science, unpublished manuscript, University of Toronto, chap. 5, p. 2.

6. For a general critique of positivism, see Max Horkheimer (1974), Critique of instrumental reason, New York: Seabury Press; see also Jurgen Habermas (1973), Theory and practice, Boston: Beacon Press, especially chap. 7. For a specific critique of the legacy of positivist thought and its influence on educational theory and practice, see Henry Giroux (1974), Ideology, culture and the process of schooling, Philadelphia: Temple University Press.

7. Herbert Marcuse (1964), One dimensional man, Boston: Beacon Press; Stuart Ewen (1975), Captains of consciousness, New York: McGraw-Hill.

8. See Joel Spring (1972), Education and the rise of the corporate state, Boston: Beacon Press; David Tyack (1974), The one best system, Cambridge, MA: Harvard University Press; Theodor Adorno \& Max Horkheimer (1972), The dialectic of enlightenment, New York: Herder and Herder.

9. Herbert Kliebard (1973). The question of teacher education. In D. McCarty (Ed.), New perspectives on teacher education. San Francisco: Jossey-Bass.

10. Kenneth M. Zeichner (1983, May-June). Alternative paradigms on teacher education. Journal of Teacher Education, 34(3), 3-9.

11. Henry A. Giroux (1984).

12. Zeicher (1983).

13. Karen J. Winkler (1984, November 7). Research focus of education doctorate is too ill-defined, officials say. The Chronicle of Higher Education, 29(11) p. 11.

14. Richard Bates (1980). Bureaucracy, professionalism and knowledge: Structures of authority structures of control. Educational Research and Perspectives, 7(2), 66-76. 
15. William S. Foster (1980, Winter). The changing administrator: Developing managerial praxis. Educational Theory, 30(1), 11-23.

16. Andrew Wake (1979). School knowledge and the structure of bureaucracy. Paper presented at the conference of the Sociological Association of Australia and New Zealand, Canberra, p. 16.

17. Michael Apple (1982). Education and power. Boston: Routledge and Kegan Paul.

18. Michael Apple (1984, Fall). The political economy of text publishing. Educational Theory, 43(4), 307-319.

19. Patrick Shannon (1984).

20. M. Katims and B. F. Jones (1981). Chicago mastery learning reading: Mastery learning instruction and assessment in inner city schools. Paper presented at the Annual Meeting of the International Reading Association, New Orleans, p. 7.

21. K. Patricia Cross (1984, November). The rising tide of school reform reports. Phi Delta Kappan, 66(3), 171.

22. Israel Scheffler (1968). University scholarship and the education of teachers. Teachers College Record, 70(1), 11.

23. Richard Hofstader (1963). Anti-intellectualism in American life. New York: Random House.

24. Paul Piccone (1981-1982, Winter). Symposium on the role of the intellectual in the 1980s. Telos, 50, 116.

25. Herbert Kohl (1983, August). Examining closely what we do. Learning, 29. 